\title{
The occurrence of cerebrovascular atherosclerosis in Alzheimer's disease patients
}

This article was published in the following Dove Press journal:

Clinical Interventions in Aging

23 May 2013

Number of times this article has been viewed

\author{
Jing Yuan ${ }^{1, *}$ \\ Ge Wen ${ }^{2, *}$ \\ Yingjia $\mathrm{Li}^{3}$ \\ Changxing Liu' \\ 'Department of Medical Information, \\ General Hospital of Jinan Military \\ Command, Jinan, People's Republic \\ of China; ${ }^{2}$ maging Center, Nanfang \\ Hospital of Southern Medical \\ University, Guangzhou, People's \\ Republic of China; ${ }^{3}$ Ultrasound \\ Diagnosis Department, Nanfang \\ Hospital of Southern Medical \\ University, Guangzhou, People's \\ Republic of China \\ *These authors contributed equally \\ to this work
}

Background: Both Alzheimer's disease (AD) and cerebrovascular atherosclerosis (CA) contributed to dementia in an aged population. Whether they share the same mechanism is unknown.

Aim: Our goal was to explore the occurrence rates of CA in $\mathrm{AD}$ patients.

Method: Here we examined the degree of CA in different groups of AD patients with contrast angiography. Ninety-three AD patients were recruited to the present study. Contrast computed tomography scanning and contrast angiography were performed for CA analyses.

Result: We found that the cerebrovascular plaques were common in AD patients, which was partly correlated with the severity of AD (as determined by cognitive decline).

Conclusion: We concluded that vascular dementia may partly correlate with AD pathology.

Keywords: Alzheimer's disease, cerebrovascular atherosclerosis, aging, patients

\section{Introduction}

Both Alzheimer's disease (AD) and cerebrovascular atherosclerosis (CA) contributed to dementia in an aged population. ${ }^{1-3}$ Whether the two diseases share a common mechanism or pathological progression is yet unclear. It is proposed that in AD the amyloid beta peptide mutates and accumulates to form abnormal aggregates that are resistant to internal clearance, ${ }^{4-6}$ and these aggregates lead to amyloid plaques (senile plaques) that cause neuronal death as well as other pathological changes inside the brain, with final functional loss. Conversely, for the CA multiple small infarcts (atheromatous plaque) formed inside microvasculature and interrupted the microperfusion. ${ }^{7-9}$ This also leads to cognitive decline and memory loss as the final result.

Given the two distinct theories explaining the pathogenesis of $\mathrm{AD}$ and $\mathrm{CA}$, there are increasing studies that show some common risk factors for both diseases, such as apolipoprotein E, age, smoking, inflammation, and body metabolism..$^{2,10-15}$ In addition, the coronary atherosclerosis cases are increased in patients with $\mathrm{AD}$ compared to those without. ${ }^{16-18}$ Conceivably, the CA is higher in patients showing heart attack. Postmortem studies also reported the existence of CA in many AD patients. In the present study, we tried to employ radiological approach to investigate the occurrence of $\mathrm{CA}$ in $\mathrm{AD}$ patients.

\section{Materials and methods Clinical data}

In the present study $93 \mathrm{AD}$ patients were recruited in the Imaging Center, Nanfang Hospital of Southern Medical University, Guangzhou, People's Republic of China 
(male, 61; female, 32; aged 59-82 years; average, 71.2 years old) from January 2012 to December 2012. The patients met the criteria of the National Institute of Neurological and Communicative Diseases and Stroke/Alzheimer's Disease and Related Disorders Association for AD, with a clinical dementia rating of 0.5 ([early AD] 17 cases); or 1 ([mild AD] 26 cases); 2 ([moderate AD] 39 cases); or 3 ([severe AD] 11 cases) (Table 1).

The study was approved by the ethics committee of medical research on human subjects at the General Hospital of Jinan Military Command, and the researchers obtained written consent from all subjects as well as their family members.

Contrast computed tomography scanning and contrast angiography were performed, atherosclerotic lesions were registered, and diameter stenosis degrees were calculated.

\section{Statistics}

The data were represented as mean \pm standard deviation and analyzed with the Statistical Package for the Social Sciences 16.0 software (SPSS; IBM Corporation, Armonk, NY, USA) for statistics. The $t$-test was used to compare intergroup differences, and $P<0.05$ was considered statistically significant.

\section{Results}

\section{Detection of cerebrovascular atherosclerosis}

We found that atheromatous plaque is prevalent in $\mathrm{AD}$ patients: six of 17 (35.3\%) in early AD; 14 of $26(53.8 \%)$ in mild $\mathrm{AD} ; 20$ of 39 (51.3\%) in moderate $\mathrm{AD}$; and nine of eleven (81.8\%) in severe AD. In addition, among these cases, both noncalcified and calcified atheromatous plaques were detected at different possibilities (Figure 1). The percentage of noncalcified mixed and calcified atheromatous plaques were $44 \%, 12 \%$, and $44 \%$ in early $\mathrm{AD} ; 47 \%, 21 \%$, and $32 \%$ in mild $\mathrm{AD} ; 39 \%, 15 \%$, and $46 \%$ in moderate $\mathrm{AD}$; and $22 \%, 35 \%$, and $43 \%$ in severe $\mathrm{AD}$ (Figure 2).

\section{Distribution of atheromatous plaques}

We found that noncalcified atheromatous plaques were mainly distributed in the intracranial arteries (79.2\%), mixed plaques in the intracranial arteries $(19.1 \%)$, and intracranial internal carotid artery (ICA) (44.3\%), calcified plaques in the intracranial ICA (55.2\%), and extracranial arteries (24.7\%) across the different $\mathrm{AD}$ groups. Interestingly, we found no obvious differences in plaque distribution across different staged AD patients $(P>0.05)$.

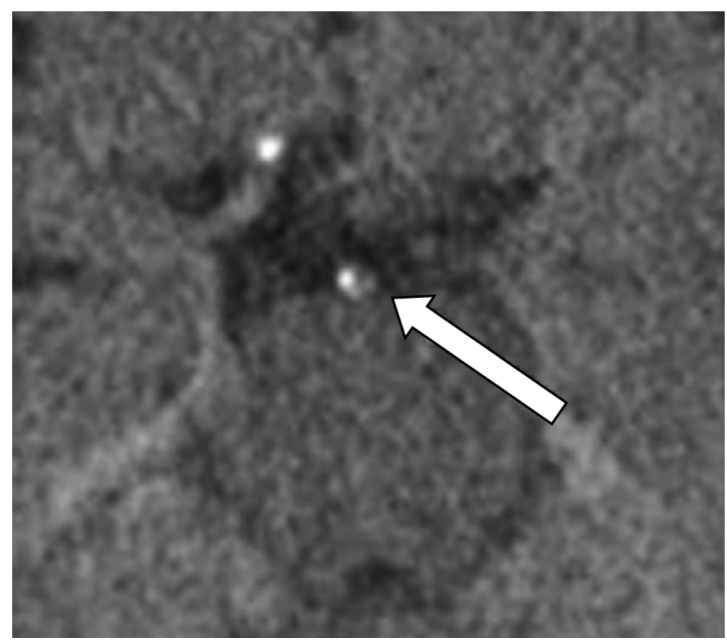

Figure I Nonenhanced CT detection of calcified atheromatous plaque (arrow) in a 72-year-old male patient with moderate AD.

Abbreviations: $C T$, computed tomography; $A D$, Alzheimer's disease.

\section{Results of atheromatous plaques as vessel occlusion}

The differentially composed atheromatous plaques have been shown to be associated with different levels of vessel occlusion previously. The percentage of severe stenosis $(>60 \%)$ and occlusion in the different $\mathrm{AD}$ groups were $3.1 \%$ (early), 6.7\% (mild), 11.3\% (moderate), and 10.7\% (severe). The values were significantly different from the severe $A D$ group to the early/mild $\mathrm{AD}$ groups.

\section{Discussion}

Few studies have examined the formation of CA plaques in AD patients, specifically. ${ }^{1,27,12}$ It has been shown that in an aged group with cognitive decline, atherosclerosis plaques could be used as the marker for vascular dementia. ${ }^{4,7,19}$

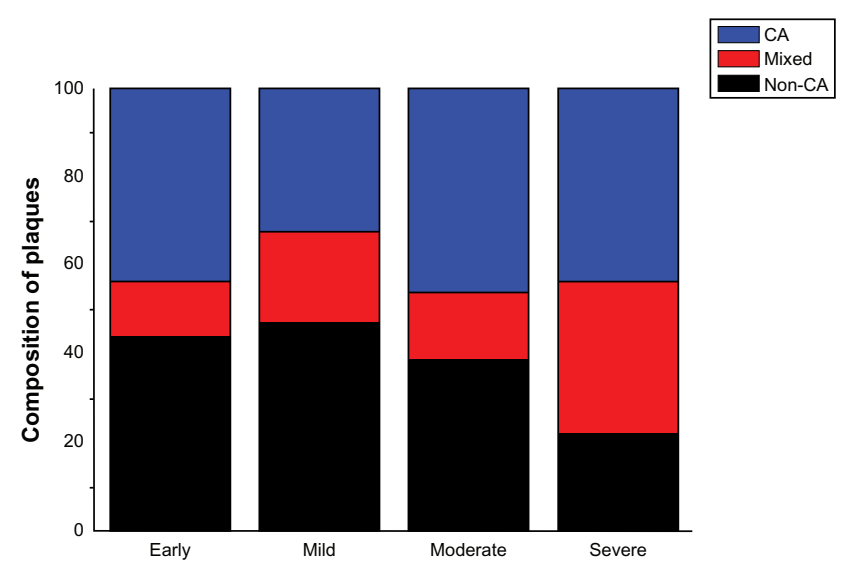

Figure 2 The composition of atheromatous plaques in different groups of $A D$ patients.

Abbreviations: AD, Alzheimer's disease; CA, calcified; Non-CA, noncalcified. 
Table I Clinical information for all patients

\begin{tabular}{llllllllll}
\hline CDR & $\begin{array}{l}\text { Number of } \\
\text { patients }\end{array}$ & Male & Female & $\begin{array}{l}\text { Mean age } \\
(\mathbf{y r})\end{array}$ & $\begin{array}{l}\text { Diabetes } \\
\text { cases }\end{array}$ & $\begin{array}{l}\text { Hypertension } \\
\text { cases }\end{array}$ & $\begin{array}{l}\text { Heart } \\
\text { disease }\end{array}$ & Smoking & Stroke \\
\hline 0.5 & 17 & 11 & 6 & 68.4 & 3 & 4 & 2 & 2 & 3 \\
1 & 26 & 16 & 10 & 71.6 & 7 & 12 & 5 & 11 & 6 \\
2 & 39 & 21 & 18 & 73.1 & 11 & 15 & 9 & 17 & 10 \\
3 & 11 & 4 & 7 & 69.8 & 2 & 4 & 3 & 5 & 2 \\
Sum & 93 & 52 & 41 & 71.2 & 23 & 35 & 19 & 35 & 21 \\
\hline
\end{tabular}

Abbreviations: CDR, clinical dementia rating; yr, year.

In the present study, we found that cerebrovascular plaques leading to stenosis or occlusion existed in $\mathrm{AD}$ patients as well. Therefore, the mixed $\mathrm{AD} / \mathrm{CA}$ pathology should be considered and referred in clinical diagnosis of certain aged patients with cognitive decline.

The mechanisms underlying such interactions are yet unclear. The common risk factors, such as apolipoprotein E, age, smoking, inflammation, and body metabolism, do not fully explain the increased atheromatous plaque occurrence in severe $\mathrm{AD}$, rather than in early $\mathrm{AD}$ patients. ${ }^{2,4,5,20-23} \mathrm{We}$ believe it is possible that the neuronal death and neuroinflammation in late-stage $\mathrm{AD}$ triggered the atheromatous plaque formation. If so, the neuroinflammation would act as the share mechanism in pathogenesis and progression in patients with severe dementia, providing the common drug target for both syndromes.

There are certain limitations of the present study. Currently, it is possible to perform magnetic resonance imaging and positron emission tomography for the tracing of plaque formation in the vessels, as well as of the amyloid plaques for $\mathrm{AD}$ patients. ${ }^{24-26}$ It will be important to perform different tests on patients to correlate the changes of CA pathology with $\mathrm{AD}$ pathology (senile/amyloid plaque) progression. Additionally, we did not correlate other syndromes of vascular dementia into the clinical data of AD patients, taken together with the analysis of stenosis changes of the vessels. ${ }^{12,27}$ We expect to perform such studies in the future. Finally, it will be important to perform these examinations on aged-matched non-AD controls to see if $\mathrm{AD}$ pathology causes increased atheromatous plaque formation.

In conclusion, we believe that the vascular pathology may represent one common phenomenon in $\mathrm{AD}$ patients. The separation of $\mathrm{AD}$ and $\mathrm{CA}$ pathology might require reconsideration.

\section{Acknowledgment}

The authors received funding from the Guangzhou Baiyun Kexunju Grant 2011-KZ-92.

\section{Disclosure}

The authors report no conflicts of interest in this work.

\section{References}

1. Roher AE, Debbins JP, Malek-Ahmadi M, et al. Cerebral blood flow in Alzheimer's disease. Vasc Health Risk Manag. 2012;8:599-611.

2. Altman R, Rutledge JC. The vascular contribution to Alzheimer's disease. Clin Sci (Lond). 2010;119(10):407-421.

3. Kennelly SP, Lawlor BA, Kenny RA. Blood pressure and the risk for dementia: a double-edged sword. Ageing Res Rev. 2009;8(2): $61-70$

4. Honjo K, Black SE, Verhoeff NP. Alzheimer's disease, cerebrovascular disease, and the $\beta$-amyloid cascade. Can J Neurol Sci. 2012;39(6): $712-728$.

5. Chu LW. Alzheimer's disease: early diagnosis and treatment. Hong Kong Med J. 2012;18(3):228-237.

6. Hooghiemstra AM, Eggermont LH, Scheltens P, van der Flier WM, Scherder EJ. Exercise and early-onset Alzheimer's disease: theoretical considerations. Dement Geriatr Cogn Dis Extra. 2012;2: $132-145$.

7. Grinberg LT, Thal DR. Vascular pathology in the aged human brain. Acta Neuropathol. 2010;119(3):277-290.

8. Veglio F, Paglieri C, Rabbia F, Bisbocci D, Bergui M, Cerrato P. Hypertension and cerebrovascular damage. Atherosclerosis. 2009; 205(2):331-341

9. Onyike CU. Cerebrovascular disease and dementia. Int Rev Psychiatry. 2006;18(5):423-431.

10. Yarchoan M, Xie SX, Kling MA, et al. Cerebrovascular atherosclerosis correlates with Alzheimer pathology in neurodegenerative dementias. Brain. 2012;135(Pt 12):3749-3756.

11. Orsucci D, Mancuso M, Ienco EC, Simoncini C, Siciliano G, Bonuccelli U. Vascular factors and mitochondrial dysfunction: a central role in the pathogenesis of Alzheimer's disease. Curr Neurovasc Res. 2013;10(1):76-80.

12. Silvestrini M, Viticchi G, Falsetti L, et al. The role of carotid atherosclerosis in Alzheimer's disease progression. J Alzheimer's Dis. 2011;25(4):719-726.

13. Palacios HH, Yendluri BB, Parvathaneni K, et al. Mitochondrionspecific antioxidants as drug treatments for Alzheimer disease. CNS Neurol Disord Drug Targets. 2011;10(2):149-162.

14. Rocchi A, Orsucci D, Tognoni G, Ceravolo R, Siciliano G. The role of vascular factors in late-onset sporadic Alzheimer's disease. Genetic and molecular aspects. Curr Alzheimer Res. 2009;6(3): 224-237.

15. Jicha GA, Parisi JE, Dickson DW, et al. Age and apoE associations with complex pathologic features in Alzheimer's disease. J Neurol Sci. 2008;273(1-2):34-39.

16. Bhat NR. Linking cardiometabolic disorders to sporadic Alzheimer's disease: a perspective on potential mechanisms and mediators J Neurochem. 2010;115(3):551-562.

17. Beeri MS, Rapp M, Silverman JM, et al. Coronary artery disease is associated with Alzheimer disease neuropathology in APOE4 carriers. Neurology. 2006;66(9):1399-1404. 
18. Kosunen O, Talasniemi S, Lehtovirta M, et al. Relation of coronary atherosclerosis and apolipoprotein E genotypes in Alzheimer patients. Stroke. 1995;26(5):743-748.

19. Moretti R, Torre P, Antonello RM, Manganaro D, Vilotti C, Pizzolato G. Risk factors for vascular dementia: hypotension as a key point. Vasc Health Risk Manag. 2008;4(2):395-402.

20. Weinstein G, Wolf PA, Beiser AS, Au R, Seshadri S. Risk estimations, risk factors, and genetic variants associated with Alzheimer's disease in selected publications from the Framingham Heart Study. J Alzheimers Dis. 2013;33 Suppl 1:S439-S445.

21. Cechetto DF, Hachinski V, Whitehead SN. Vascular risk factors and Alzheimer's disease. Expert Rev Neurother. 2008;8(5):743-750.

22. Rafael H. Cerebral atherosclerosis and mild Alzheimer's disease. Stroke. 2003;34(8):e106.

23. Premkumar DR, Cohen DL, Hedera P, Friedland RP, Kalaria RN. Apolipoprotein E-epsilon4 alleles in cerebral amyloid angiopathy and cerebrovascular pathology associated with Alzheimer's disease. Am J Pathol. 1996;148(6):2083-2095.
24. Musiek ES, Saboury B, Mishra S, et al. Feasibility of estimation of brain volume and 2-deoxy-2-(18)F-fluoro-D-glucose metabolism using a novel automated image analysis method: application in Alzheimer's disease. Hell J Nucl Med. 2012;15(3):190-196.

25. Westman E, Muehlboeck JS, Simmons A. Combining MRI and CSF measures for classification of Alzheimer's disease and prediction of mild cognitive impairment conversion. Neuroimage. 2012;62(1): 229-238.

26. Manook A, Yousefi BH, Willuweit A, et al. Small-animal PET imaging of amyloid-beta plaques with [11C]PiB and its multi-modal validation in an APP/PS1 mouse model of Alzheimer's disease. PLoS One. 2012;7(3):e31310.

27. Kalback W, Esh C, Castano EM, et al. Atherosclerosis, vascular amyloidosis and brain hypoperfusion in the pathogenesis of sporadic Alzheimer's disease. Neurol Res. 2004;26(5):525-539.
Clinical Interventions in Aging

\section{Publish your work in this journal}

Clinical Interventions in Aging is an international, peer-reviewed journal focusing on evidence-based reports on the value or lack thereof of treatments intended to prevent or delay the onset of maladaptive correlates of aging in human beings. This journal is indexed on PubMed Central, MedLine, the American Chemical Society's 'Chemical Abstracts

\section{Dovepress}

Service' (CAS), Scopus and the Elsevier Bibliographic databases. The manuscript management system is completely online and includes a very quick and fair peer-review system, which is all easy to use. Visit http://www.dovepress.com/testimonials.php to read real quotes from published authors. 